\title{
Colour variation of the Maltese wall lizards (Podarcis filfolensis) at population and individual levels in the Linosa island
}

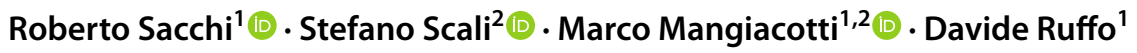

Received: 19 February 2021 / Accepted: 14 June 2021 / Published online: 8 July 2021

(c) The Author(s) 2021

\begin{abstract}
The research on animal colouration has always been of great interest for biologists but since the last decades it has grown exponentially thanks to multidisciplinary approaches. Animals have found several ways to deal with the camouflage/communication trade-off in colouration, leading to the evolution of alternative patterns of variation of colourations at different levels including signal partitioning and spatial resolution of colouration. In this paper we analyse the variability of dorsal and ventral colouration in males and females of Maltese wall lizards in three populations on Linosa. We collected highresolution digital images of dorsal, ventral and throat colouration from 61 lizards (32 males and 29 females). We showed that the colouration differs among sexes and body regions within the same individual. Colourations are also variable among individuals within population, as well as among different populations across the Island. Finally, we detected a lizard's colouration shifts with increasing body size. Those result supports the hypothesis that colouration in this species evolved under the competing pressures of natural and sexual selection to promote signals that are visible to conspecifics while being less perceptible to avian predators.
\end{abstract}

\section{Graphic abstract}
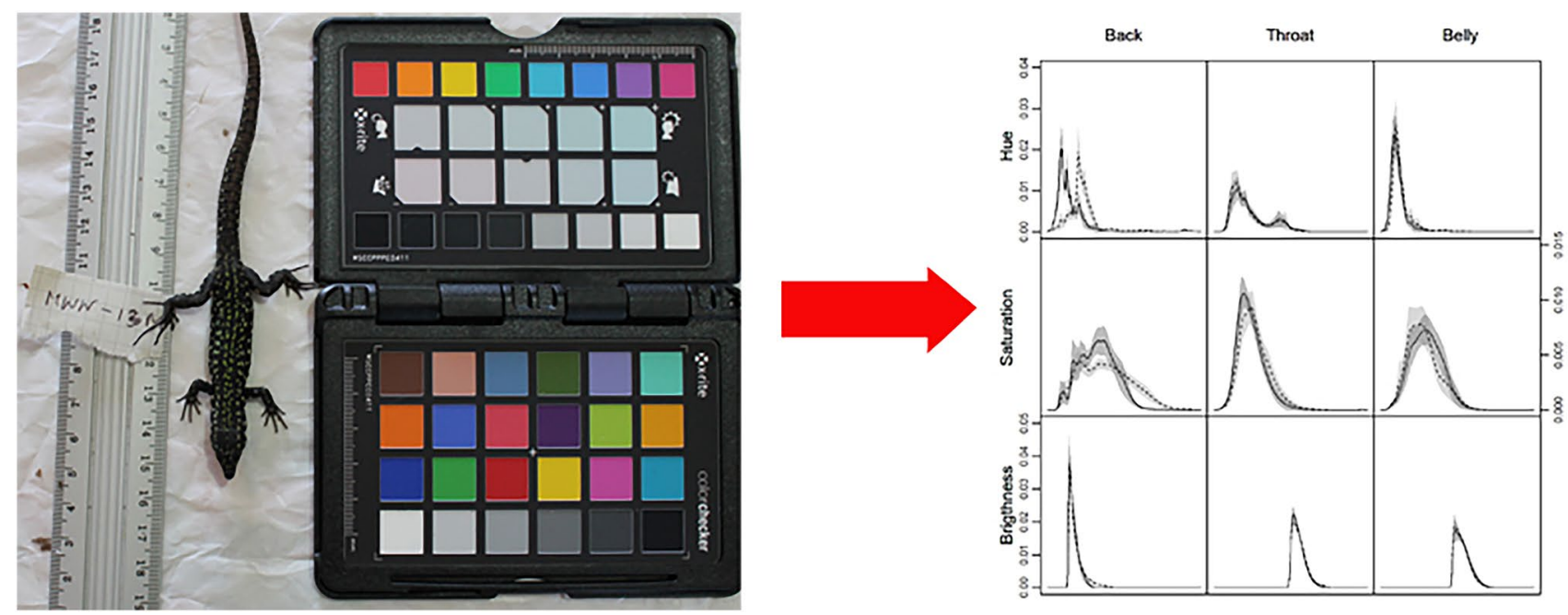

Keywords Colour variation · Sexual vs natural selection $\cdot$ HSV colour system $\cdot$ Sexual dimorphism $\cdot$ Podarcis filfolensis

Roberto Sacchi

roberto.sacchi@unipv.it

Extended author information available on the last page of the article 


\section{Introduction}

Since the last decades research on animal colourations has been attracting increasing interest, and it is a fast-growing interdisciplinary branch of research involving genetics, developmental biology, feeding ecology, behaviour and reproductive biology (Cuthill et al. 2017). As a matter of fact, the evolution of body colourations is more often the result of the interaction between synergic and conflictual pressures rather than the outcome of one single factor (Endler 1981; Stuart-Fox and Moussalli 2009; Cuthill et al. 2017). Notably, mimicry for predator escaping and conspicuousness for communication promotes opposite adjustments in colouration, as crypsis reduces the contrast between animal colour and background, whereas signalling needs bright and flashy colours, which increase the contrast with the background (Marshall and Stevens 2014; Franklin et al. 2020).

Animals have found several ways to deal with the camouflage/communication trade-off in colouration, leading to the evolution of alternative patterns of variation of colourations at different levels, i.e., among individuals within the same population, among different body portions within the same individual, as well as over time, as occurring for seasonally colour changes. Evolutionary solutions for the conflicting adjustments between camouflage and communication include (i) signal partitioning, in which body regions visible to predators are used for camouflage and body regions hidden from potential predators are used for signalling (Stuart-Fox and Ord 2004), (ii) colours that are not visible to predators but only to conspecifics, like UV or polarized light (Cummings et al. 2003; Siebeck et al. 2010; Abramjan et al. 2020), (iii) spatial resolution of colouration in a way that colour is conspicuous only at a short distance, while at distance colours blend matching the background (Barnett et al. 2018), and (iv) changing colourations that become cryptic or conspicuous when necessary (Stuart-Fox et al. 2008), or (v) altering signalling behaviours when predators are present (Endler 1987).

In this perspective, reptiles, notably lizards, are excellent model species, as they exhibit simultaneous camouflage and sexual signals. Several studies have actually shown that dorsal colourations in lizards which are more exposed to birds hunting exhibit lower sexual dichromatism and conspicuousness, whereas less exposed ventral regions are more visible to conspecifics and exhibit more conspicuous sexual signals (Marshall and Stevens 2014; Stuart-Fox et al. 2004; Stuart-Fox and Ord 2004). There is increasing evidence that lizards may have different visual sensitivities than their predators, e.g., in the UV spectrum (Ellingson et al. 1995; Fleishman et al. 1993; Loew 1994; Pérez i De Lanuza and Font 2014), even if birds can perceive the UV spectrum (Teodore and Nilsson 2019). Therefore, lizards have the potential to use visual signals that are more conspicuous to conspecific than to predator vision, minimizing the risk of detection (Brandley et al. 2013). Furthermore, the ability to rapidly change colour has evolved in several species of lizards, enabling individuals to match different backgrounds (Stuart-Fox et al. 2008), but also express conspicuous signals only when they are really effective (Endler 1987; Stuart-Fox et al. 2008).

The Maltese wall lizards (Podarcis filfolensis) is an endemic lacertid of the Maltese and Pelagian Islands, although in the Lampedusa Island the species has been only recently introduced (Lo Cascio et al. 2011). The status of the Linosa population is still unclear, since molecular analyses did not rule out neither possibility of a human introduction, neither the possibility of natural long-distance rafting (Salvi et al. 2014). A general feature of Maltese wall lizards is that individuals tend to be highly variable in colour and markings, especially among different islands. Lizards on Malta, Gozo and Camino are smaller and much lighter in colour having a grey, brown or green ground colour with darker markings on the back and sides (Schembri 1986). Lizards on Linosa and Lampione have dark backs with green-bluish spots, while ventral regions appear white with red-brown spots (Lo Cascio et al. 2011). To our knowledge the causes of this variability, notably the relative importance of camouflage and communication, are still unclear. Here, we analyse the variability of dorsal and ventral colouration in males and females of Maltese wall lizards in three populations on Linosa, to assess whether the colouration of the species has adapted for conspicuous visual signalling to conspecifics while minimizing detection by predators through decreased conspicuousness and signal partitioning. To do so we used digital image analysis to quantitatively analyse colour variability among individuals within a population and among different body regions within an individual as well, taking into account the effects of sexes and ontogeny (size).

\section{Methods}

\subsection{Data sampling}

We collected the field data during spring 2016 in three localities from the volcanic island of Linosa $\left(35^{\circ} 52^{\prime} \mathrm{N}\right.$, $\left.12^{\circ} 52^{\prime} \mathrm{E}\right)$ : the first is the crater of Monte Nero, the second is the crater of Monte Rosso, the third is the village of Mannarazza in the centre of the island. Sampling surveys were performed in each site by two researchers for three consecutive days and all lizards were captured by noosing or by hand, and kept singularly in cotton bags until measurements and photographs. Individuals were sexed and measured for 
snout-to-vent length (SVL), using a ruler (1 $\mathrm{mm}$ accuracy). All juveniles (SVL $<50$ mm, Moravec 1993; Lo Cascio et al. 2011) were excluded from the data. Overall, we measured 61 lizards, including 32 males and 29 females. For each individual, we took high-resolution digital images of dorsal, ventral and throat colouration using a Nikon D50 camera at a 1.2-million-pixel resolution, equipped with a Nikkor $60 \mathrm{~mm}$ AF-S Micro lens, and fixed on a stand at a distance of $18 \mathrm{~cm}$ (Sacchi et al. 2013). Each picture was taken adjacent to a GretagMacBeth Mini ColorChecker chart ( 24 colour references, $5.7 \mathrm{~cm} \times 8.25 \mathrm{~cm}$ ) in a $44 \times 44 \mathrm{~cm}$ lightbox illuminated with two daylight $22 \mathrm{~W}$ circular neon tubes (Reporter 55100 Studio-kit). Overall, we obtained a sample of 183 images. After data collection, all lizards were released healthy in the respective capture spot.

\subsection{Colour analysis}

We analysed the pictures in the RGB colour system according to the method by Bergmann and Beehner (2008) and Sacchi et al. (2013). Firstly, the Camera plug-in for Adobe Photoshop CS3 was used to generate a new colour profile that adjusted the colour in the photographs (jpeg format) to the known colour levels in each square of the ColorChecker chart. Then, for each image, we selected the 'region of interest' (ROI) using the 'lazoo' tool, and pixels corresponding to point of reflected light and black spots were removed using the package "magick" in R (Ooms 2018). Consequently, we analysed on average 6501 pixels for image, ranging from 507 to 26,780. Finally, the RGB colour values were rearranged in the Hue, Saturation, and Value (HSV) system.

\subsection{Statistical analyses}

We assessed colour variation in Maltese wall lizards following a three-steps analysis as in Sacchi et al. (2020): we first used the values computed on the whole samples of pixel selected for each individual to generate the individuals' frequency distributions of hue, saturation, and brightness using (HSV colour spectrum). Second, we used the colour spectra to perform three principal component analyses (PCA), one for $\mathrm{H}, \mathrm{S}$, and $\mathrm{V}$ respectively, and we used the first components, explaining, respectively, $46.7 \%, 49.8 \%$ and $76.5 \%$ of the total variance, as a proxy to summarize the inter-individual variability of colouration. The hue PC score accounted for the opposite variation of the orange-yellow and green interval in the hue colour spectrum (Fig. S1), in a way that negative scores associated with a higher peak in the orange-yellow interval whereas positive scores associated with a higher peak in the green interval. The saturation PC score accounted for the increase of colour saturation with increasing score (Fig. S1), whereas the value PC score accounted for the increase of brightness with higher scores (Fig. S1). Third, we analysed the variation of the PC scores through random intercept linear mixed models (LMM), one for $\mathrm{H}$, $\mathrm{S}$, and $\mathrm{V}$ respectively. Fixed effects were the sex, body region and body size (i.e., standardized SVL). The twoway interactions sex $\times$ body region, $\operatorname{sex} \times$ body size, and body size $\times$ body region were also added to account for possible differential effects of sex, body region, and size on colour expression. Population $\left(\sigma_{\text {pop }}^{2}\right)$ and individual (as nested effect within populations, $\sigma^{2}$ ind/pop) entered the model as random effects. LMMs were fit in a Bayesian analytical framework available in the package JAGS 4.3.0 (http://mcmc-jags.sourceforge.net/), using flat priors for coefficients and intercept $(\mu=0$ and $\sigma=0.001$ ), and uninformative half-Cauchy priors $\left(x_{0}=0, \gamma=25\right)$ for $\sigma_{\text {error }}^{2}, \sigma_{\text {pop }}^{2}$, and $\sigma_{\text {ind/pop }}^{2}$. For all models, Markov Chain Monte Carlo parameters were set as follows: number of independent chains $=$ three; number of iterations $=34,000$; burn-in $=4000$; thinning $=$ three. We checked for convergence and used the amount of variance explained by the model $\left(R_{\text {LMM }}^{2}\right)$ as a goodness-of-fitmeasure. $R_{\text {LMM }}^{2}$ for Bayesian models was computed following the procedure proposed for linear mixed-effects models (Snijder and Bosker 1999; Nakagawa and Schielzeth 2013). In detail, the $R_{\text {LMM }}^{2}$ for each model was obtained as the ratio of the variance explained by the fixed effects $\left(\sigma_{\mathrm{f}}^{2}\right)$ and the sum of the variance components of the model $\left(\sigma_{\mathrm{f}}^{2}+\sigma_{\text {ind/pop }}^{2}+\sigma_{\text {pop }}^{2}+\sigma_{\text {error }}^{2}\right)$. Similarly, the intraclass correlation coefficients (ICC) for the random effects were computed as $\sigma_{\text {pop }}^{2}\left(\sigma_{\text {pop }}^{2}+\sigma_{\text {error }}^{2}\right)$ for the population effect, $\left(\sigma_{\text {ind/pop }}^{2}+\sigma_{\text {pop }}^{2}\right) /\left(\sigma_{\text {ind/pop }}^{2}+\sigma_{\text {pop }}^{2}+\sigma_{\text {error }}^{2}\right)$, for the effect of the individual within population.

Results from the posterior distributions are reported as the half-sample mode (HSM, Bickel and Frühwirth 2006) plus $95 \%$ (or 50\%) highest density intervals $\left(\mathrm{HDI}_{95} ; \mathrm{HDI}_{50}\right.$, Kruschke 2010). In Bayesian statistics, the HSM is a commonly used estimator of the central tendency of posterior probability distribution robust to outliers, whereas the $\mathrm{HDI}_{95}$ defines the interval that includes the parameter with $95 \%$ probability. Parameter values in the centre of the HDI have higher credibility than parameter values at the limits of the interval. Therefore, when the HDIs of two groups do not overlap, there is a credible evidence for different group means. By contrast, to the extent the two groups' HDIs overlap there is evidence of no credible difference between the means. When comparing two groups (e.g., males and females), we therefore reported the posterior probability of their difference being different (i.e., higher or lower) from zero. Data preparation, model settings, call to JAGS, and posterior elaborations were done in $\mathrm{R} 4.0$ ( $\mathrm{R}$ Core Team 2018) using the package R2jags (Su and Yajima 2015), modeest (Poncet 2012), and HDInterval (Meredith and Kruschke 2018). 


\section{Results}

The HSV spectra computed for dorsal and ventral colourations of Maltese lizards (Fig. 1) revealed a clear sexual dimorphism in back colouration, males displaying a greener and more brilliant colouration than females. Pattern of sexual dimorphism was less evident in both throat and belly colouration (Fig. S1).
Overall, the Bayesian mixed models captured (conditioned $R^{2}$ ) 62.1\% ( $\left.\mathrm{HDI}_{95}: 48.3-9.1 \%\right), 53.8 \%\left(\mathrm{HDI}_{95}\right.$ : $32.3-99.9 \%)$, and $95.4 \%\left(\mathrm{HDI}_{95}: 94.0-99.4 \%\right)$ of the full variance for hue, saturation, and brightness, respectively. The fixed effects alone $\left(R^{2}\right)$ represented $43.3 \%\left(\mathrm{HDI}_{95}\right.$ : 1.0-55.4\%), $19.9 \%\left(\mathrm{HDI}_{95}: 0.1-32.6 \%\right)$, and $92.4 \%\left(\mathrm{HDI}_{95}\right.$ : $12.2-95.2 \%$ ) of the full variance for hue, saturation, and brightness, respectively.

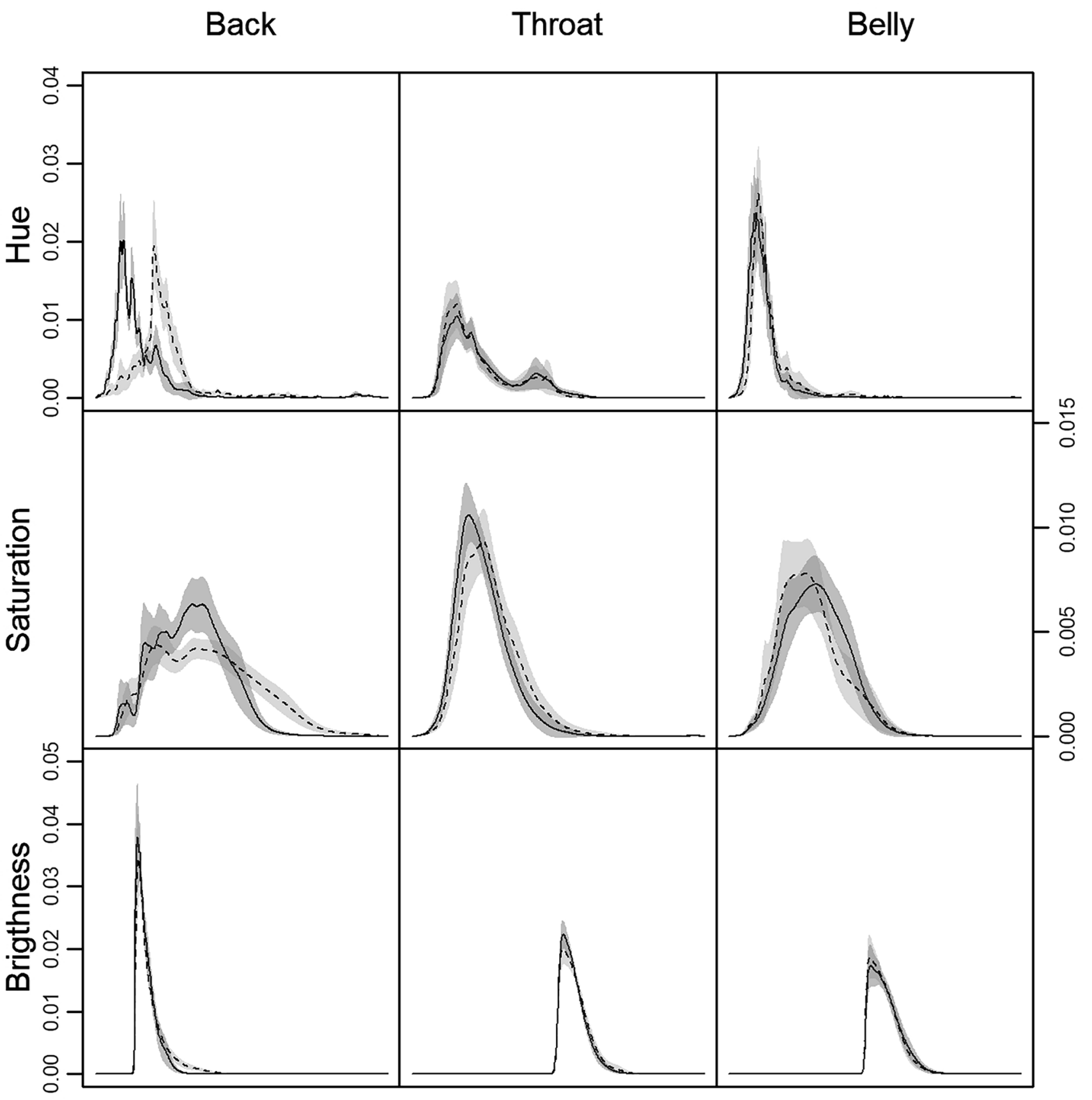

Fig. 1 Distribution frequencies of hue, saturation and brightness for back, throat and belly of Maltese wall lizards in the Linosa Island. Solid lines and dark grey area are for females, dashed lines and light grey areas are for males. Lines are means and area represent $\mathrm{HDI}_{95}$ 
Bayesian models supported the occurrence of a difference in the back colouration between males and females (Fig. 1), as the posterior distributions of the difference between sexes $(\hat{\jmath}-$ o $)$ deviated from zero for hue and brightness, but not for saturation values (Table 1). In details, males were greener $\left(P_{\delta>\uparrow}>0.99\right)$ and more brilliant $\left(P_{\delta>\uparrow}>0.99\right)$ than females, but dorsal colouration was as saturated in males as in female $\left(P_{\delta>\circ}=0.68\right)$. Throat colouration was greener and more saturated in males than females (Fig. 2), but the difference did not deviate enough from zero to be fully credible (hue: $P_{\partial^{\lambda}>}=0.79$; saturation: $P_{\delta^{\prime}>\uparrow}=0.80$, Table 1 ). Throat was as brilliant in males as in females $\left(P_{\widehat{\gamma}>\uparrow}=0.34\right.$, Table 1). The belly colouration was also greener in males than females, but, as for throat, the difference did not sensibly deviate from zero $\left(P_{\widehat{\partial}>\uparrow}=0.87\right.$, Table 1$)$. Saturation and brightness were similar in male and female belly (saturation: $P_{\delta>\uparrow}=0.29$; brightness: $P_{\delta>\uparrow}=0.59$, Table 1).

In males, the hue did not differ between back and throat $\left(P_{\text {th }>\text { ba }}=0.28\right.$, Table 2$)$, but colour was greener in throat than in belly $\left(P_{\text {th }>\text { be }}>0.99\right.$, Table 2, Fig. 2). Colouration was more saturated and less brilliant than both throat and belly ( $P>0.99$ in all cases, Table 2$)$. Consequently, saturation and brightness were similar in throat and belly colourations ( $P_{\text {th }>\text { be }}: 0.89$ and 0.68 respectively). In females, throat was greener than both back and belly (Fig. 1), as the posterior probability of the difference in the hue values sensibly deviated from zero in both cases (both $P>0.99$, Table 2). Throat colour was less saturated than both back and belly colourations (Fig. 2), as shown by deviation from zero of the posterior probabilities (Table $2, P>0.99$ in both cases). Consequently, colour saturation resulted similar in back and belly (Table $2, P_{\mathrm{ba}>\mathrm{be}}=0.80$ ). As for males, colour in both throat and belly was much more brilliant than back colour (Table 2, $P>0.99$ in both cases).

Bayesian LMMs showed a strong effect of body size on colour in all the three body regions, especially for the colour hue (Fig. 2). Notably, dorsal and ventral colourations had opposite patterns (Fig. 2). In both sexes back colour was greener in larger than in smaller individuals $\left(P_{\beta \text { svl }>0}>0.92\right)$, whereas the opposite occurred for throat and belly colours $\left(P_{\beta s v l<0}>0.79\right)$. Consequently, the dorsal and ventral colourations contrasted one another much more intensively in larger individuals of both sexes.
However, the effect of size differed between sexes, and females had a steeper slope than males (Fig. 2, $P_{\varphi>0}$ exceed 0.99 ), in a way that colour difference between sexes decreased with increasing size (Table 3 ). The model did not detect any effect of body size on colour saturation in any body region of males $\left(P_{\beta s v l \neq 0}<0.68\right.$, Fig. 2$)$, whereas slight, negative effects emerged in females for back $\left(P_{\beta \mathrm{svl}<0}=0.89\right.$, Fig. 2$)$ and belly $\left(P_{\beta \mathrm{svl}<0}=0.85\right.$, Fig. 2), but not for throat $\left(P_{\beta s v l<0}=0.45\right.$, Fig. 2). Therefore, larger females had less saturated dorsal and ventral (belly) colourations than smaller ones. Accordingly to these opposed patterns, there was enough support for a difference of the effect of body size on colour saturation between sexes $\left(P_{\delta>\uparrow}=0.88\right.$, Fig. 2$)$, in a way that males become more saturated than females with increasing body size (Table 3). Finally, we found a strong effect of body size on brightness of back in both males $\left(P_{\beta \text { svl }<0}=0.99\right.$, Fig. 2) and females $\left(P_{\beta \text { svl }<0}=0.89\right.$, Fig. 2$)$, but not in the other two body regions $\left(P_{\beta s v l \neq 0}<0.74\right.$, Fig. 2$)$. In both sexes larger individual had a less brilliant back colouration than smaller individuals, and this effect was more pronounced in females than in males $\left(P_{\delta>\uparrow}=0.96\right.$, Table 3$)$.

Finally, a large portion of the variance unexplained by the fixed effects (sex, season, and body size) depended on the populations and individuals within populations, especially for saturation (Table 4). Indeed, the intraclass correlation coefficients (ICC) for saturation in both populations and individuals within population were $0.28\left(\mathrm{HDI}_{95}\right.$ : 0.01-0.99) and $0.40\left(\mathrm{HDI}_{95}: 0.11-0.99\right)$ respectively, suggesting that saturation differed among populations as well as among individuals within the same population (Fig. 3). A similar, but less evident pattern occurred also for colour hue, as the ICCs were $0.19\left(\mathrm{HDI}_{95}: 0.01-0.99\right)$ and 0.29 $\left(\mathrm{HDI}_{95}:\right.$ 0.04-0.99) for populations and individuals within population respectively. Therefore, hue varied both among populations and among individuals within the same population (Fig. 3). The ICCs for colour brightness were 0.34 $\left(\mathrm{HDI}_{95}: 0.03-0.99\right)$ and $0.35\left(\mathrm{HDI}_{95}: 0.04-0.99\right)$ for populations and individuals within populations, respectively. However, the pattern of variability of brightness resulted less evident than those observed for hue and saturation (Fig. 3).
Table 1 Sexual dichromatism in Maltese wall lizards

\begin{tabular}{llrr}
\hline Body region & Hue & \multicolumn{1}{l}{ Saturation } & \multicolumn{1}{l}{ Brightness } \\
\hline Back $_{\hat{\delta}-\uparrow}$ & $\mathbf{0 . 0 6 1}(0.026$ to 0.097$)$ & $0.011(-0.014$ to 0.036$)$ & $\mathbf{0 . 0 2 7}(0.012$ to 0.041$)$ \\
Throat $_{\widehat{\delta}-\uparrow}$ & $0.014(-0.021$ to 0.05$)$ & $0.016(-0.009$ to 0.041$)$ & $-0.003(-0.018$ to 0.011$)$ \\
Belly $_{\hat{\delta}-\uparrow}$ & $0.022(-0.014$ to 0.058$)$ & $-0.007(-0.032$ to 0.018$)$ & $0.002(-0.013$ to 0.016$)$ \\
\hline
\end{tabular}

For each component of the colour spectrum and body region, the posterior distribution of the difference $\delta^{\lambda}-q$ is synthetized as the half-sample mode (HSM) and the $95 \%$ highest density intervals $\left(\mathrm{HDI}_{95}\right.$; in parenthesis); the HSM values with associated $\mathrm{HDI}_{95}$ not including zero are bolded 

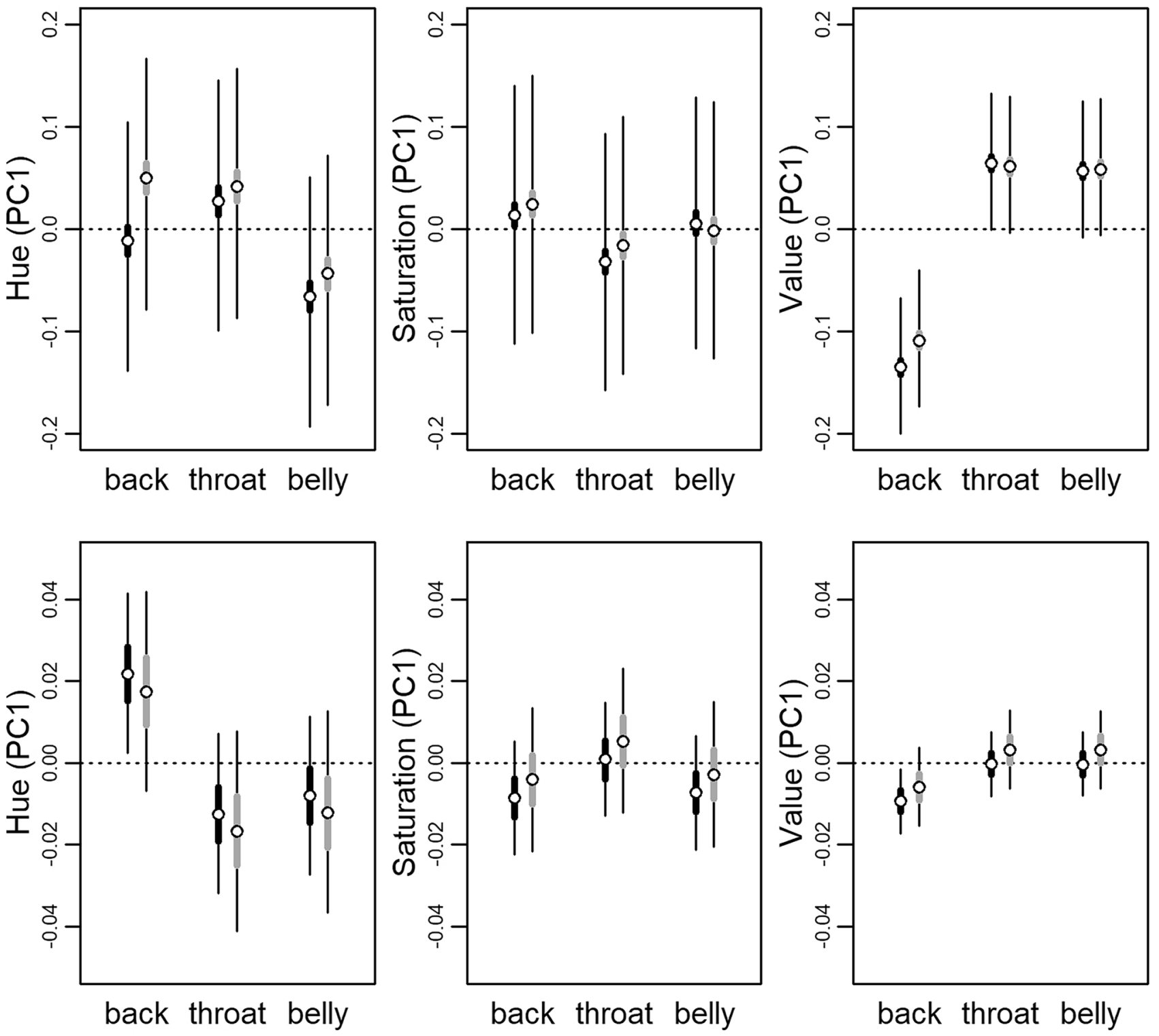

Fig. 2 Posterior probability distributions of the PC1 values of hue, saturation and brightness in back, throat and belly of Maltese wall lizards in the Linosa Island as estimated by LMMs. Upper panels report differences between sexes in each body; lower panels report the effect

\section{Discussion}

Our results show that the colouration of Maltese wall lizards differs among sexes and body regions within the same individual, and it is variable among individuals within population, as well as among different populations across the Linosa Island. Also, a lizard's colouration shifts with its body size (Galan 2008).

Firstly, we supported sexual dichromatism in this species (Lo Cascio et al. 2011), as males were both greener and more brilliant on back, and greener and more saturated on throat compared to females, as it commonly occurs in of body size (SVL) on colouration in males and females in each of the three body regions. HSM (white circles), $\mathrm{HDI}_{50}$ (thick lines), and $\mathrm{HDI}_{95}$ (thin lines) estimates are shown; females are in black, males in grey

Lacertidae species (e.g., Olsson et al. 1994). The analyses on HSV values did not include the predominant black markings and stripes, but only the coloured spots dispersed in the dark background. Therefore, our results suggested that males could be more conspicuous than females, and females relatively more camouflaged than males. Two opposed selective pressures could have caused this pattern, namely intrasexual selection for conspicuous signals in males, and natural selection for concealing colourations in females. This is not surprising, as in Podarcis species, males commonly experience intrasexual competition (López and Martín 2001; Pérez i de Lanuza et al. 2013b, 2017; Marshall and Stevens 2014; 
Table 2 Variability of colouration among different body region of the same individual in males and females of the Maltese wall lizard

\begin{tabular}{|c|c|c|c|c|c|c|}
\hline & \multicolumn{3}{|l|}{ Back } & \multicolumn{3}{|l|}{ Throat } \\
\hline & Hue & Saturation & Brightness & Hue & Saturation & Brightness \\
\hline \multicolumn{7}{|l|}{ Males } \\
\hline Throat & $\begin{array}{l}-0.008(-0.036 \text { to } \\
0.020)\end{array}$ & $\begin{array}{l}-\mathbf{0 . 0 4 0}(-0.06 \text { to } \\
-0.021)\end{array}$ & $\mathbf{0 . 1 7 0}(0.158$ to 0.182$)$ & & & \\
\hline Belly & $\begin{array}{l}\mathbf{- 0 . 0 9 4}(-0.122 \text { to } \\
-0.065)\end{array}$ & $\begin{array}{l}-\mathbf{0 . 0 2 6}(-0.045 \text { to }- \\
0.007)\end{array}$ & $\mathbf{0 . 1 6 7}(0.155$ to 0.179$)$ & $\begin{array}{l}-\mathbf{0 . 0 8 5}(-0.114 \text { to } \\
-0.057)\end{array}$ & $\begin{array}{l}\mathbf{0 . 0 1 4}(-0.005 \text { to } \\
0.033)\end{array}$ & $\begin{array}{l}-0.003(-0.015 \text { to } \\
0.009)\end{array}$ \\
\hline \multicolumn{7}{|c|}{ Females } \\
\hline Throat & $\mathbf{0 . 0 3 9}(0.010$ to 0.068$)$ & $\begin{array}{l}\mathbf{- 0 . 0 4 6}(-0.065 \text { to } \\
-0.026)\end{array}$ & $\mathbf{0 . 2 0 0}(0.187$ to 0.212$)$ & & & \\
\hline Belly & $\begin{array}{l}-0.054(-0.084 \text { to } \\
0.025)\end{array}$ & $\begin{array}{l}-0.008(-0.028 \text { to } \\
0.012)\end{array}$ & $\mathbf{0 . 1 9 2}(0.18$ to 0.205$)$ & $\begin{array}{l}-\mathbf{0 . 0 9 3}(-0.122 \text { to }- \\
0.064)\end{array}$ & $\mathbf{0 . 0 3 8}(0.018$ to 0.058$)$ & $\begin{array}{l}-0.008(-0.02 \text { to } \\
0.005)\end{array}$ \\
\hline
\end{tabular}

The HSM values with associated $\mathrm{HDI}_{95}$ not including zero are bolded

Table 3 Variation of colour with increasing body size (SVL) between sexes and among different body region of the same individual of the Maltese wall lizard

\begin{tabular}{llll}
\hline & Hue & Saturation & Brightness \\
\hline Males vs females & $\mathbf{- 3 . 4 2 5}(-5.741$ to -1.085$)$ & $0.939(-0.643$ to 2.518$)$ & $0.907(-0.079$ to 1.89$)$ \\
Throat vs back & $\mathbf{- 2 . 9 7 3}(-5.304$ to -0.637$)$ & $0.132(-1.441$ to 1.702$)$ & $0.909(-0.076$ to 1.891$)$ \\
Belly vs back & $-0.411(-2.999$ to 2.092$)$ & $0.442(-1.405$ to 2.333$)$ & $0.349(-0.601$ to 1.308$)$ \\
Back vs belly & $2.558(-0.867$ to 6.000$)$ & $0.315(-2.109$ to 2.787$)$ & $-0.558(-1.921$ to 0.824$)$ \\
\hline
\end{tabular}

The HSM values with associated $\mathrm{HDI}_{95}$ not including zero are bolded

\begin{tabular}{lllr}
\hline & Hue & Saturation & \multicolumn{1}{l}{ Brightness } \\
\hline$\sigma_{\text {fixed }}^{2}$ & $0.244(0.179-0.318)$ & $0.044(0.027-0.066)$ & $0.747(0.697-0.799)$ \\
$\sigma_{\text {pop }}^{2}$ & $0.050(0.001-22.99)$ & $0.039(0.001-125.1)$ & $0.020(0.001-5.302)$ \\
$\sigma_{\text {ind/pop }}^{2}$ & $0.026(0.001-0.083)$ & $0.021(0.002-0.052)$ & $<0.001(0.000-0.006)$ \\
$\sigma_{\text {error }}^{2}$ & $0.216(0.168-0.281)$ & $0.099(0.076-0.130)$ & $0.039(0.031-0.049)$ \\
\hline
\end{tabular}

Table 4 Posterior probability distributions (HDM and $\mathrm{HDI}_{95}$ ) for the variances of fixed effects $\left(\sigma_{\text {fixed }}^{2}\right)$, random effects $\left(\sigma_{\text {pop }}^{2}\right.$, $\left.\sigma_{\text {ind/pop }}^{2}\right)$, and error $\left(\sigma_{\text {error }}^{2}\right)$ not change with age, not increase the chances of being detected by predators (e.g., Marshall and Stevens 2014).

Interestingly, males throat was more saturated and brilliant than belly. Throat colouration could signal more efficiently than belly, because it can be raised up when signalling to conspecific or raised down to be hidden away when predators are present (Endler 1987). Male displays in Podarcis species typically involve head raising and even head-bobbing (thus revealing the colours of the throat, e.g., Pérez i de Lanuza et al. 2013a), but lateral distension of the body in a posture (that would reveal significant parts of the lizard's belly surface) have never been reported. More generally, sexual dichromatism in Maltese wall lizard actually involves both back and throat, so both colourations may be used in intraspecific communication, in a multicomponent communication system. However, natural selection constrains dichromatism more intensively on 'exposed' body regions (as lizard's back) than on 'concealed' body regions (as lizard's throat), whereas dimorphism in ornamentation is driven primarily by sexual selection (Stuart-Fox and Ord 

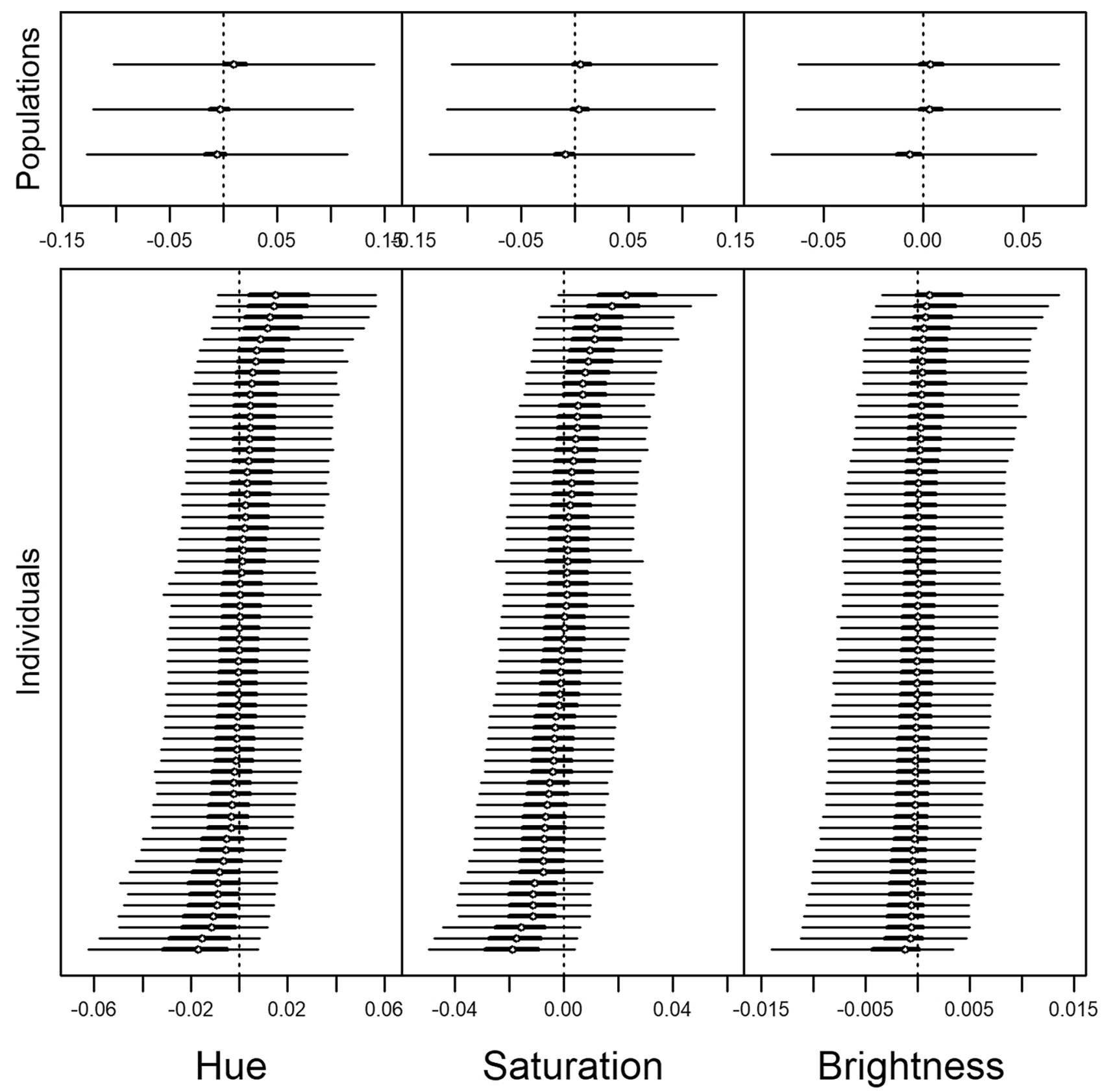

Fig. 3 Bayesian model predictions of hue, saturation and brightness of colouration (PC1 Scores) for the among populations variation (upper panels) and among individuals within population variation

2004). This might explain why green/bluish coloured spots featuring dorsal and ventral colourations are expressed on a dark/black background on the back, and on a white/brilliant background on the throat. Dorsal ornamentation could therefore best work as a 'public' signal always visible to all conspecific of both sexes, whereas the throat colouration as a 'private' signals visible only to few (one) conspecifics during bouts of display in combats or female courting (Espmark et al. 2000). From the point of view of the (lower panels) in Maltese wall lizards of the Linosa Island. Circle indicates HSM, thick and thin lines represent $\mathrm{HDI}_{50}$ and $\mathrm{HDI}_{95}$, respectively

trade-off between camouflage and communication, we could say that the Maltese wall lizard is adopting a sort of signal partitioning, as more exposed body regions (back) are better camouflaged and used for long-distance communication, compared to covert body regions (throat) that are much more conspicuous and devoted to short distance and more intense communication.

Colour of Maltese wall lizards sensibly changed with individual size in both sexes, but with opposite patterns in 
upper- and under-parts of the body, suggesting the occurrence of ontogenetic variation that promotes increased contrast between dorsal and ventral colourations. Size is one of the first determinant of the outcome of a dyadic contest in lizards (Sacchi et al. 2009, 2021). Therefore, reliably predicting the size of potential opponents is crucial for males, to avoid engaging in costly and not necessary combats. In this perspective, the ontogenetic pattern of colour variation in Maltese wall lizards would act as signals, or as amplifiers of body size, to facilitate receivers' assessment of body size (Names et al. 2019a), especially in the first stages of a confrontation, when lizards must assess the opponent quality at a certain distance (Baeckens et al. 2018). Although being informative, correlations between colour and body size arise because of simple ontogenetic processes, as for darkening which follows accumulation of melanin covering other pigments (Cuervo and Shine 2007; Names et al. 2019b) or for the onset of sexual maturity (Galán 2008). In this study we focussed only on adult and sexually mature individuals, so we could reliably exclude that the ontogenetic pattern we observed would be due to onset of sexual maturity. The observed pattern of variation has been previously described for Iberolacerta monticola, where the bright dorsal colouration of males gradually changes with age over a period of several years, during which the brown scales gradually turned green (Galán 2008). So, the green patches play a conspicuous role as sexual signal, while the irregular or reticulated markings play a cryptic function, and consequently do not vary throughout the lifetime of lizards (Galán 2008). We assume that dorsal colouration in P. filfolensis is actually working in a similar way as in I. monticola, i.e., the bluish/green spots are used for communication, while the black irregular background is functional to camouflage. Therefore, the trade-off between camouflage and communication could have been evolutionary solved through the spatial resolution of colouration, in a way that colour is conspicuous only at a short distance, while at distance colours blend matching the background (Barnett et al. 2018).

The variability of colouration at both individual and population levels could reflect the effects on colouration due to the variability in individual condition within population, and to the variability in habitat features (i.e., background colour) among localities, respectively. In species with pronounced intrasexual competition, as in Podarcis species, male specific intense colourations typically act as quality signals to determine the outcome of intrasexual aggressions for territories or mates. To be honest, colour signals must correlate with fitness-relevant traits, such as body size, health, parasites, vulnerability, to name a few. Therefore, only high-quality individuals are able to afford the costs for displaying intense colouration, and this limitation is enough to generate and maintain colour variability among individuals (Iwasa et al. 1991). Colour variation among individuals within population supports the idea that green/bluish spots on both back and throat in this species might be used (by males) to communicate with conspecifics.

The variability of colouration among individuals at population levels can be interpreted in terms of optimization of camouflage in response to the variability of background. Linosa is a volcanic island with peculiar and adverse pedoclimatic conditions hosting a vegetation dominated by pseudo-steppe with grasses and annuals, Mediterranean and predesert scrub (Pasta et al. 2017), on substrates dominated by dark black to brown/reddish rocks. Two out of the three populations we sampled were in the surrounding of the top of the two volcanic craters, with black and brown rocks respectively ("Monte Nero" and "Monte Rosso" stand literally for Black and Red Mountain, respectively). By contrast, we sampled the third population within the village of Manarazza, which is surrounded by a thicker and higher vegetation than the two previous sites, in addition to human crops (mainly, capers, lentils and vineyards). Lizards in Manarazza were greener and more saturated than individuals from other populations. Further, lizards from Monte Nero were the darkest of all. Therefore, our results support the hypothesis that body colouration might allow individuals to match colour background, to maximize camouflage, and minimize the risk of detection by (avian) predators (Stevens et al. 2013; Brandley et al. 2013; Marshall and Stevens 2014).

In conclusion, our data indicate that colouration in Maltese wall lizards may have evolved under the competing pressures of natural and sexual selection to promote signals that are visible to conspecifics while being less perceptible to avian predators. We also found that the evolutionary solution to trade-off between camouflage and communication could involve a combination of different processes, such as signal partitioning to specific body regions and signal resolution.

Supplementary Information The online version contains supplementary material available at https://doi.org/10.1007/s12210-021-01010-3.

Author contributions All authors contributed to the study conception and design. Material preparation, data collection and analysis were performed by all authors. The first draft of the manuscript was written by RS and all authors commented on previous versions of the manuscript. All authors read and approved the final manuscript.

Funding Open access funding provided by Università degli Studi di Pavia within the CRUI-CARE Agreement. Research has been funded by the "Fondo Ricerca e Giovani" (FRG) (Ministry of Education, University and Research-MIUR) to Roberto Sacchi.

Availability of data and material Not applicable.

Code availability Not applicable.

\section{Declarations}

Conflict of interest The authors declare that they have no conflict of interest. 
Ethics approval The Ministry of Education, University and Research (MIUR) provided all the authorizations for the study (Aut. Prot. PNM0015024, 2005-2017).

\section{Consent to participate Not applicable}

Consent for publication Not applicable.

Open Access This article is licensed under a Creative Commons Attribution 4.0 International License, which permits use, sharing, adaptation, distribution and reproduction in any medium or format, as long as you give appropriate credit to the original author(s) and the source, provide a link to the Creative Commons licence, and indicate if changes were made. The images or other third party material in this article are included in the article's Creative Commons licence, unless indicated otherwise in a credit line to the material. If material is not included in the article's Creative Commons licence and your intended use is not permitted by statutory regulation or exceeds the permitted use, you will need to obtain permission directly from the copyright holder. To view a copy of this licence, visit http://creativecommons.org/licenses/by/4.0/.

\section{References}

Abramjan A, Baranová V, Frýdlová P et al (2020) Ultraviolet reflectance and pattern properties in leopard geckos (Eublepharis macularius). Behav Process 173:104060. https://doi.org/10.1016/j. beproc. 2020.104060

Baeckens S, Driessens T, Huyghe K et al (2018) Intraspecific variation in the information content of an ornament: Why relative dewlap size signals bite force in some, but not all island populations of Anolis sagrei. Integr Comp Biol 58:25-37. https://doi.org/10. 1093/icb/icy012

Barnett JB, Cuthill IC, Scott-Samuel NE (2018) Distance-dependent aposematism and camouflage in the cinnabar moth caterpillar (Tyria jacobaeae, Erebidae). R Soc Open Sci 5:171396. https:// doi.org/10.1098/rsos.171396

Bergman TJ, Beehner JC (2008) A simple method for measuring colour in wild animals: validation and use on chest patch colour in geladas (Theropithecus gelada). Biol J Linn Soc 94:231-240. https:// doi.org/10.1111/j.1095-8312.2008.00981.x

Biaggini M, Bombi P, Capula M, Corti C (2010) Podarcis muralis (Laurenti, 1768). In: Corti C, Capula M, Luiselli L, Razzetti E (eds) Fauna d'Italia. Calderini, Bologna, pp 391-401

Bickel DR, Frühwirth R (2006) On a fast, robust estimator of the mode: comparisons to other robust estimators with applications. Comput Stat Data Anal 50:3500-3530. https://doi.org/10.1016/j.csda. 2005.07.011

Brandley NC, Speiser DI, Johnsen S (2013) Eavesdropping on visual secrets. Evol Ecol 27:1045-1068. https://doi.org/10.1007/ s10682-013-9656-9

Carpenter GC (1995) Modeling dominance: the influence of size, coloation, and experience on dominance relations in tree lizards (Urosaurus ornatus). Herpetol Monogr 9:88-101

Castilla AM, Gosá A, Galán P, Pérez-Mellado V (1999) Green tails in lizards of the genus Podarcis: do they influence the intensity of predation? Herpetologica 55:530-537. https://doi.org/10.2307/ 3893319

Coladonato AJ, Mangiacotti M, Scali S et al (2020) Morph-specific seasonal variation of aggressive behaviour in a polymorphic lizard species. PeerJ 8:e10268. https://doi.org/10.7717/peerj.10268

Cook EG, Murphy TG, Johnson MA (2013) Colorful displays signal male quality in a tropical anole lizard. Naturwissenschaften 100:993-996. https://doi.org/10.1007/s00114-013-1095-5
Cuervo JJ, Shine R (2007) Hues of a dragon's belly: morphological correlates of ventral coloration in water dragons. J Zool 273:298-304. https://doi.org/10.1111/j.1469-7998.2007.00328.x

Cummings ME, Rosenthal GG, Ryan MJ (2003) A private ultraviolet channel in visual communication. Proc R Soc London Ser B Biol Sci 270:897-904. https://doi.org/10.1098/rspb.2003.2334

Cuthill IC, Allen WL, Arbuckle K et al (2017) The biology of color. Science 357:eaan0221. https://doi.org/10.1126/science.aan0221

Ellingson JM, Fleishman LJ, Loew ER (1995) Visual pigments and spectral sensitivity of the diurnal gecko Gonatodes albogularis. J Comp Physiol A 177:559-567. https://doi.org/10.1007/BF002 07185

Endler JA (1981) An overview of the relationships between mimicry and crypsis. Biol J Linn Soc 16:25-31. https://doi.org/10.1111/j. 1095-8312.1981.tb01840.x

Endler JA (1987) Predation, light intensity and courtship behaviour in Poecilia reticulata. PoecUiidae, Pisces

Espmark Y, Amundsen T, Rosenqvist G (2000) Animal signals: signalling and signal design in animal communication. Tapir Academic Press, Trondheim

Fleishman LJ, Loew ER, Leal M (1993) Ultraviolet vision in lizards [6]. Nature 365:397

Franklin AM, Marshall J, Feinstein AD et al (2020) Differences in signal contrast and camouflage among different colour variations of a stomatopod crustacean, Neogonodactylus oerstedii. Sci Rep 10:1-14. https://doi.org/10.1038/s41598-020-57990-z

Galán P (2008) Ontogenetic and sexual variation in the coloration of the lacertid lizards Iberolacerta monticola and Podarcis bocagei. Do the females prefer the greener males? Anim Biol 58:173-198

Iwasa Y, Pomiankowski A, Nee S (1991) The evolution of costly mate preferences II. The "handicap" principle. Evolution (n Y) 45:1431-1442. https://doi.org/10.1111/j.1558-5646.1991.tb026 46. $\mathrm{x}$

Kruschke JK (2010) Bayesian data analysis. Wiley Interdiscip Rev Cogn Sci 1:658-676. https://doi.org/10.1002/wcs.72

LeBas NR, Marshall NJ (2000) The role of colour in signalling and male choice in the agamid lizard Ctenophorus ornatus. Proc $\mathrm{R}$ Soc London B Biol Sci 267:445-452. https://doi.org/10.1098/ rspb.2000.1020

Lo Cascio P, Corti C, Capula M (2011) Podarcis filfolensis (Bedriaga, 1876). In: Corti C, Capula M, Luiselli L et al (eds) Fauna d'Italia, Reptilia. Calderini, Bologna, pp 381-387

Loew ER (1994) A third, ultraviolet-sensitive, visual pigment in the Tokay gecko (Gekko gekko). Vis Res 34:1427-1431. https://doi. org/10.1016/0042-6989(94)90143-0

López P, Martín J (2001) Fighting rules and rival recognition reduce costs of aggression in male lizards Podarcis Hispanica. Behav Ecol Sociobiol. https://doi.org/10.1007/s002650000288

Marshall KLA, Stevens M (2014) Wall lizards display conspicuous signals to conspecifics and reduce detection by avian predators. Behav Ecol 25:1325-1337. https://doi.org/10.1093/beheco/aru126

Martin J, Lopez P (1996) Avian predation on a large lizard (Lacerta lepida) found at low population densities in Mediterranean habitats: aAn analysis of bird diets. Copeia. https://doi.org/10.2307/ 1447538

Meredith M, Kruschke J (2018) HDInterval: Highest (Posterior) density intervals. R package version 0.2.2. https://CRAN.R-project. org/package $=$ HDInterval

Moravec J (1993) Captive breeding of Podarcis filfolensis. In: Valakos ED, Bohme W, Pérez-Mellado V, Maragou P (eds) Lacertids of the Mediterranean Basin. Hellenic Zoological Society, Athens, Bonn, Alicante, pp 243-248

Nakagawa S, Schielzeth H (2013) A general and simple method for obtaining $R^{2}$ from generalized linear mixed-effects models. Met Ecol Evol 4:133-142. https://doi.org/10.1111/j.2041-210x.2012. 00261.x 
Names G, Martin M, Badiane A, Le Galliard JF (2019a) The relative importance of body size and UV coloration in influencing male-male competition in a lacertid lizard. Behav Ecol Sociobiol 73:1-14. https://doi.org/10.1007/s00265-019-2710-z

Names G, Martin M, Badiane A, Le Galliard JF (2019b) The relative importance of body size and UV coloration in influencing malemale competition in a lacertid lizard. Behav Ecol Sociobiol 73:98. https://doi.org/10.1007/s00265-019-2710-z

Olsson M, Gullberg A, Tegelströ H (1994) Sperm competition in the sand lizard, Lacerta agilis. Anim Behav 48:193-200

Ooms J (2018) magick: advanced graphics and image-processing in R. R package version 2.3. https://CRAN.R-project.org/package $=$ magick

Pasta S, Ardenghi NMG, Badalamenti E et al (2017) The alien vascular flora of Linosa (Pelagie Islands, Strait of Sicily): update and management proposals. Willdenowia 47:135. https://doi.org/10. 3372/wi.47.47205

Pérez I De Lanuza G, Font E (2014) Ultraviolet vision in lacertid lizards: Evidence from retinal structure, eye transmittance, SWS1 visual pigment genes and behaviour. J Exp Biol 217:2899-2909. https://doi.org/10.1242/jeb.104281

Pérez i de Lanuza G, Carazo P, Font E (2014) Colours of quality: structural (but not pigment) coloration informs about male quality in a polychromatic lizard. Anim Behav 90:73-81. https://doi.org/10. 1016/j.anbehav.2014.01.017

Pérez i de Lanuza G, Font E, Carazo P (2013a) Color-assortative mating in a color-polymorphic lacertid lizard. Behav Ecol 24:273279. https://doi.org/10.1093/beheco/ars164

Pérez i de Lanuza G, Font E, Monterde JL (2013b) Using visual modelling to study the evolution of lizard coloration: sexual selection drives the evolution of sexual dichromatism in lacertids. J Evol Biol 26:1826-1835. https://doi.org/10.1111/jeb.12185

Pérez i de Lanuza G, Carretero MÁ, Font E (2017) Intensity of malemale competition predicts morph diversity in a colour polymorphic lizard. Evolution ( $\mathrm{n}$ y). https://doi.org/10.1111/evo.13256

Poncet P (2012) modeest: mode estimation. R package version 2.4.0. https://CRAN.R-project.org/package=modeest

R Core Team (2018) R: a language and environment for statistical computing. R Foundation for Statistical Computing, Vienna, Austria. https://www.R-project.org/

Sacchi R, Pupin F, Gentilli A et al (2009) Male-male combats in a polymorphic lizard: residency and size, but not color, affect fighting rules and contest outcome. Aggress Behav 35:274-283. https:// doi.org/10.1002/ab.20305

Sacchi R, Pellitteri-Rosa D, Bellati A et al (2013) Colour variation in the polymorphic common wall lizard (Podarcis muralis): an analysis using the RGB colour system. Zool Anz 252:431-439. https://doi.org/10.1016/j.jcz.2013.03.001

Sacchi R, Cancian S, Ghia D et al (2020) Color variation in signal crayfish Pacifastacus leniusculus. Curr Zool. https://doi.org/10. 1093/cz/zoaa031
Sacchi R, Coladonato AJ, Battaiola M et al (2021) Subjective resource value affects aggressive behavior independently of resource-holding-potential and color morphs in male common wall lizard. J Ethol. https://doi.org/10.1007/s10164-021-00690-6 (in Press)

Salvi D, Schembri PJ, Sciberras A et al (2014) Evolutionary history of the Maltese wall lizard Podarcis filfolensis: insights on the 'Expansion-Contraction' model of Pleistocene biogeography. Mol Ecol 23:1167-1187. https://doi.org/10.1111/mec.12668

Schembri PJ (1986) The Maltese wall lizard. Civilization 27:741-743

Siebeck UE, Parker AN, Sprenger D et al (2010) A species of reef fish that uses ultraviolet patterns for covert face recognition. Curr Biol 20:407-410. https://doi.org/10.1016/j.cub.2009.12.047

Snijders T, Bosker R (1999) Multilevel analysis: an introduction to basic and advanced multilevel modeling. Sage, London

Stevens M, Rong CP, Todd PA (2013) Colour change and camouflage in the horned ghost crab Ocypode ceratophthalmus. Biol J Linn Soc 109:257-270. https://doi.org/10.1111/bij.12039

Stuart-Fox DM, Ord TJ (2004) Sexual selection, natural selection and the evolution of dimorphic coloration and ornamentation in agamid lizards. Proc R Soc B Biol Sci 271:2249-2255. https://doi. org/10.1098/rspb.2004.2802

Stuart-Fox DM, Moussalli A (2009) Camouflage, communication and thermoregulation: lessons from colour changing organisms. Philos Trans R Soc B Biol Sci 364:463-470. https://doi.org/10.1098/ rstb.2008.0254

Stuart-Fox DM, Moussalli A, Johnston GR, Owens IPF (2004) Evolution of color variation in dragon lizards: quantitative tests of the role of crypsis and local adaptation. Evolution (n Y) 58:1549 1559. https://doi.org/10.1111/j.0014-3820.2004.tb01735.x

Stuart-Fox DM, Moussalli A, Whiting MJ (2008) Predator-specific camouflage in chameleons. Biol Lett 4:326-329. https://doi.org/ 10.1098/rsbl.2008.0173

Su U, Yajima M (2015) R2jags: Using R to Run 'JAGS'. R package version 0.6-1. https://CRAN.R-project.org/package=R2jags

Teodore C, Nilsson DE (2019) Avian UV vision enhances leaf surface contrasts in forest environments. Nature Commun 10:238. https:// doi.org/10.1038/s41467-018-08142-5

Thompson CW, Moore MC (1991) Throat colour reliably signals status in male tree lizards, Urosaurus ornatus. Anim Behav 42:745-753. https://doi.org/10.1016/S0003-3472(05)80120-4

Whiting MJ, Stuart-Fox DM, O'Connor D et al (2006) Ultraviolet signals ultra-aggression in a lizard. Anim Behav 72:353-363. https:// doi.org/10.1016/j.anbehav.2005.10.018

Publisher's Note Springer Nature remains neutral with regard to jurisdictional claims in published maps and institutional affiliations.

\section{Authors and Affiliations}

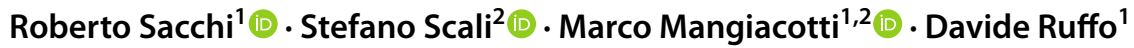

Stefano Scali

stefano.scali@comune.milano.it

Marco Mangiacotti

marco.mangiacotti01@universitadipavia.it

Davide Ruffo

davide.jhon.ruffo@gmail.com
1 Department of Earth and Environmental Sciences, University of Pavia, Viale Taramelli 24, 27100 Pavia, Italy

2 Museo di Storia Naturale di Milano, Corso Venezia 55, 20121 Milan, Italy 